\title{
SUSTENTABILITAT CLIVELLADA. DE LA GESTIÓ HIDROLÒGICA A L'OBRA HIDRÀULICA AL VINALOPÓ MODERN
}

\section{CRACKED SUSTAINABILITY. FROM HYDRAULIC MANAGEMENT TO HYDRAULIC WORKS IN MODERN-DAY VINALOPÓ}

Tomàs Pérez Medina

\begin{abstract}
RESUM
Davant la crisi d'insustentabilitat dels ecosistemes aquàtics, hem de revisar les nocions bàsiques per a canviar la visió actual de rius i aqüífers. Per la qual cosa és indispensable plantejar el procés històric de formació d'aquest problema socioecològic. Com era la gestió de l'aigua a les comunitats rurals del Vinalopó a l'època moderna? Quines idees i coneixements aplicava el camperolat tardofeudal quan utilitzava i/o s'apropiava del medi natural i, per tant, de l'aigua? A partir del llegat històric i patrimonial dels segles XVII i XVIII també deduïm els primers clivells a la gestió hidrològica ecointegradora de la comunitat rural i el pas a les grans obres hidràuliques que trenquen la sustentabilitat del cicle de l'aigua i dels seus ecosistemes.
\end{abstract}

Paraules clau: Vinalopó, aigua, sustentabilitat, camperolat, obra hidràulica.

\begin{abstract}
In light of the crisis of unsustainability of aquatic ecosystems, the basic notions must be reviewed in order to change the current perception of rivers and aquifers. It is therefore essential to consider how this socio-ecological problem was historically constructed. How was water managed in rural communities of the River Vinalopó during the modern era? What ideas and knowledge did the late-feudal peasantry apply when using and/or taking over the natural environment, and therefore the water? From the historic and patrimonial legacy of 17 th and 18 th centuries we also learn about the first breaches of eco-conciliatory hydraulic management of the rural community. From there we see the transition to big hydraulic works which break the sustainability of the water cycle and its ecosystems.
\end{abstract}

Keywords: Vinalopó, water, sustainability, peasantry, hydraulic work. 
L'actualitat de la falta d'aigua en gran part de la conca del riu Vinalopó, igual que a d'altres comarques meridionals, fa del subministrament, usos i administració hídrica tema de portada al País Valencià. Des d'àmbits estatals, tècnics i empresarials, les propostes planificadores i legislatives davant la problemàtica de l'aigua parteixen d'unes suposicions convertides en axiomes als estudis i cossos legals: dèficit, excedents, demandes, conques excedentàries i deficitàries, desequilibris hídrics. Tots són conceptes clau en la gestió actual de l'aigua que, des d'una noció constructiva i enginyera clàssica, ha conduït al foment i la continuació d'un model estructuralista basat en la creació d'infraestructures hidràuliques de gran escala i impacte (embassaments, canals, transvasaments, perforacions...). Certament, la creació d'infraestructures hidràuliques és condició necessària i element essencial per a desenvolupar una política de gestió de l'aigua, particularment als països com el nostre de variable i accentuada estacionalitat de les precipitacions. La necessitat d'obres de captació, regulació i distribució són, doncs, imprescindibles. Ara bé, des de l'àmbit de la història, com des dels estudis comparatius etnogràfics, antropològics i geogràfics, i des de les actuals propostes de l'ecologia social lamb una nova visió socioeconòmica i política), s'evidencia que la necessitat hídrica no justifica qualsevol obra en qualsevol lloc.

La persistència d'un conjunt d'idees i concepcions al voltant de l'aigua, dels hidromites, simplifica i falseja l'anàlisi i el diagnòstic de la realitat física hidrològica (Martínez Fernández, 2002: 23-27). El paradigma basat en una visió utilitarista de la natura, considerada imperfecta, que cal dominar $\mathrm{i}$ corregir amb la tècnica industrial, ens ha portat a un atzucat d'insustentabilitat. Quan s'origina aquest model de gestió de l'aigua fonamentat en tòpics hidràulics? Com i perquè els conceptes de desequilibri hidràulic, conques excedentàries i deficitàries, demandes hídriques i escassesa estructural es converteixen en indiscutibles a la gestió de l'aigua?

Davant la crisi d'insustentabilitat dels ecosistemes aquàtics, hem de revisar les nocions bàsiques per a canviar la visió patrimonialista de rius $\mathrm{i}$ aqüífers (Arrojo, 2006: 19-21). També és indispensable plantejar el procés històric de la formació d'aquest problema socioecològic. Com era la gestió de l'aigua a les comunitats rurals del Vinalopó a l'època moderna? Quines 
idees i coneixements aplicava el camperolat tardofeudal quan utilitzava i/o s'apropiava del medi natural i, per tant, de l'aigua? A partir del llegat històric i patrimonial que encara perdura a les comarques del Vinalopó, podem deduir els primers clivells a la gestió hidrològica ecointegradora de la comunitat rural $\mathrm{i}$ el pas a les grans obres hidràuliques que trenquen la sustentabilitat del cicle de l'aigua i els seus ecosistemes.

L'època moderna és un període de construcció prèvia, de preparatius per als canvis capitalistes dels segles XIX i XX, de formació primitiva del model conceptual i econòmic vigent actualment. L'aigua deixa de ser considerada element clau dels ecosistemes. L'aigua és separada del seu cicle natural per a integrar-la dins un nou circuit. De l'aigua com a component dels ecosistemes naturals es passa a l'aigua com a recurs natural antropitzat, que a la modalitat capitalista es considera bé productiu-mercantil. Dins d'aquest procés històric de la nova concepció de la natura i de l'aigua com a bé apropiable i productiu es situa el regalisme il.lustrat i l'ús intensiu de l'aigua i de l'energia hidromecànica. Al llarg de l'època moderna, període de transició del feudalisme al capitalisme, es donaren canvis ideològics $\mathrm{i}$ institucionals -a més de socio-econòmics- que generaren les noves nocions de recursos, bens, producció, creixement i riquesa que desenvolupa el capitalisme (Naredo, 1987). L'humanisme i l'antropocentrisme renaixentistes obriren un important portell en la concepció organicista de la natura, que va dirigir-se cap a la concepció mecanicista elaborada des de finals del segle XVII -postulats newtonians.

\section{El riU, el Clima I l'aigua}

El Vinalopó és un petit riu del migjorn valencià que al llarg de $89^{\prime} 5 \mathrm{~km}$ de longitud rep les aigües de muntanyes i vessants que, a través de rambles i barrancs, drenen $1.705 \mathrm{~km}^{2}$. El riu Vinalopó és un riu autòcton, com ho són el rius menors valencians (Sénia, Cérvol, Segarra, Sec de Betxí, Morvedre, Serpis, Girona, Gorgos, Montnegre...). Les seues dimensions i caràcters hidrològics no es poden comparar amb els importants rius al.lòctons que, després de recórrer l'interior muntanyós peninsular, creven transversalment el País Valencià per a desembocar a la mar Mediterrània (Millars, Túria, Xúquer i Segura). Són rius amb aigua continua i regular al llarg de tot l'any, amb un cabal important i un aparat hidràulic d'envergadura amb afluents llargs i cabalosos. El petit riu Vinalopó manca d'aigua la major part de les estacions; únicament en alguns trams una font hi humiteja el llit uns quilòmetres. L'aforament del riu Vinalopó al pas pel terme de la vila d'Asp és de $0^{\prime} 44 \mathrm{~m}^{3} / \mathrm{seg}$. La irregularitat, el llit sec i pedregós, l'abundància de nombrosos barrancs i torrents fan del Vinalopó riu-rambla. 
Però no hem d'oblidar que la percepció que actualment tenim dels cursos fluvials, com és el riu Vinalopó, està intervinguda i transformada per les polítiques hidràuliques aplicades des de finals del segle XIX. Són unes actuacions hidràuliques basades en l'extracció d'aigua subterrània, la construcció de preses i altres infraestructures i els transvasaments interconques. Tot això per abastir els nous extensos regadius creats al llarg del segle XX, a més de l'infinit consum urbà, industrial, comercial i turístic, que ha provocat canvis als règims fluvials durant la darrera centúria'.

Llevada la capçalera del riu Vinalopó que històrica, cultural i econòmicament s'ha integrat a les comarques de la Vall d'Albaida i de l'Alcoià, a grans trets es distingeixen tres comarques al complex ambiental de la conca del riu Vinalopó: I'Alt Vinalopó, les Valls del Vinalopó i el Baix Vinalopó. Totes tres mantenen unes característiques ambientals mediterrànies, però entre l'interior elevat, el sector central i la planura costanera elxana, apareixen diferències estructurals i paisatgístiques evidents que denoten biòtops i factors ecològics diferents. Contrastos i matisos que es manifesten als diferents espais hidràulics de la conca.

El sud del País Valencià pertany a l'àrea climàtica mediterrània amb accentuada sequedat estivenca, per l'escassesa pluviomètrica i les elevades temperatures superiors a $22^{\circ} \mathrm{C}$ a l'estiu. Així, doncs, l'evaporació i l'aridesa estival en són característiques bàsiques de la comarca. La sequedat, com a qüestió climatològica basada a la mesura de la pluviositat i la temperatura, predomina a les terres del Vinalopó. Les dades anuals amaguen altres trets destacats als vessants climàtics mediterranis. Un és la irregularitat interanual de les precipitacions amb alternança d'anys plujosos i anys secs. Aquest caràcter de la pluviometria comarcal és un factor important per a l'adaptació dels agroescosistemes comarcals i provocarà contínues pregaries per l'aigua. Per altra banda, també destaca el caràcter esporàdic i tempestuós de les precipitacions mediterrànies, que sovintegen més a la

1 Els canvis són quantitatius i qualitatius. El riu Vinalopó ostenta el rècord de la contaminació hídrica al País Valencià. Les seues aigües no superen en cap punt del seu curs el valor de $60 \mathrm{a}$ I'Índex de Qualitat General. Per a avaluar la qualitat de les aigües superficials s'utilitza I'IQG elaborat a partir de 23 paràmetres significatius, com són les matèries en suspensió, la conductivitat, el PH, l'oxigen dissolt, sulfats, cadmi... L'escassesa de cabal, els vessaments urbans i, molt especialment, els industrials (química, calcer, pells adobades, tèxtil, paper, marbre...) provoquen la pèssima qualitat del riu Vinalopó (Almenar, Bono i García, 2000: 242). 


\section{TAULA 1}

Temperatura i precipitacions mitjanes de Beneixama, Novelda i Elx

\begin{tabular}{|l|l|l|c|c|c|c|c|c|c|c|c|c|c|}
\hline \multirow{2}{*}{ BeneIXAMA } & Anual & $\mathrm{G}$ & $\mathrm{F}$ & $\mathrm{M}$ & $\mathrm{A}$ & $\mathrm{M}$ & $\mathrm{J}$ & $\mathrm{J}$ & $\mathrm{A}$ & $\mathrm{S}$ & $\mathrm{O}$ & $\mathrm{N}$ & $\mathrm{D}$ \\
& $555 \mathrm{~mm}$ & 32,6 & $32^{\prime} 1$ & 44,8 & 57,1 & 51,1 & 46,0 & 25,9 & 15,6 & 62,3 & 68,0 & 59,0 & 60,4 \\
& $13,9^{\circ} \mathrm{C}$ & 6,0 & 7,0 & 9,0 & 11,4 & 15,2 & 19,5 & 23,5 & 23,4 & 20,2 & 14,8 & 9,5 & 6,5 \\
\hline NovelDA & $316 \mathrm{~mm}$ & $19^{\prime} 1$ & $19^{\prime} 7$ & $26^{\prime} 9$ & $36^{\prime} 7$ & $28^{\prime} 6$ & $28^{\prime} 3$ & 9 & 11 & 34 & $43^{\prime} 4$ & $37^{\prime} 2$ & $21^{\prime} 9$ \\
& $17^{\prime} 3^{\circ} \mathrm{C}$ & $10^{\prime} 7$ & $11^{\prime} 5$ & $13^{\prime} 4$ & $15^{\prime} 1$ & $17^{\prime} 9$ & 22 & $25^{\prime} 5$ & $25^{\prime} 4$ & $22^{\prime} 7$ & $18^{\prime} 4$ & $13^{\prime} 9$ & $10^{\prime} 8$ \\
\hline ELX & $239 \mathrm{~mm}$ & $14^{\prime} 3$ & $19^{\prime} 1$ & $18^{\prime} 5$ & $21^{\prime} 2$ & $21^{\prime} 7$ & $18^{\prime} 7$ & $4^{\prime} 5$ & $5^{\prime} 3$ & $24^{\prime} 0$ & $39^{\prime} 4$ & $31^{\prime} 8$ & $20^{\prime} 2$ \\
& $20,1^{\circ} \mathrm{C}$ & 12,5 & 13,8 & 15,8 & 18,1 & 21,6 & 25,8 & 28,8 & 28,5 & 25,9 & 21,1 & 16,1 & 12,9 \\
\hline
\end{tabular}

Elaboració a partir de Pérez Cueva, 1994: 170 i 179

tardor i primavera. En uns dies s'arreplega un elevat percentatge de la precipitació anual, que pot arribar a $100 \mathrm{~mm}$ en unes hores. Els diluvis omplin sobtadament rambles i barrancs ${ }^{2}$.

Els ecosistemes i biòtops desenvolupats hi són adaptats perfectament a les singularitats bioclimàtiques: la vegetació és normalment llenyosa, de fulles menudes i dures; esclerofília que permet suportar l'estrès hídric i les diferències climàtiques anuals. La lentitud del creixement arbori és l'efecte immediat de l'escassesa hídrica. Arbres, matolls, herbàcies i espècies de fauna del domini biogeogràfic mediterrani s'ajusten a aquestes varietats naturals del medi ambient. Planes, muntanyes i vessants mostren el matoll d'aquesta varietat climàtica: romaní, timó, espart, coscoll, llentiscle...

2 Encara que utilitzem dades actuals, hem d'incidir en un aspecte bàsic de la climatologia i, en conseqüència, dels ecosistemes mediterranis: el canvi climàtic actual. Els dos segles d'era fòssil ha augmentat la concentració de $\mathrm{CO}_{2}$ un $35 \%$. En conseqüència, la temperatura del planeta s'ha incrementat al segle $\mathrm{XX}$ en $0^{\prime} 7^{\circ} \mathrm{C} \mathrm{i}$, en concret, a la península lbèrica la temperatura ha augmentat $1^{\prime} 3^{\circ} \mathrm{C}$ les últimes tres dècades. Segons les previsions, per a mitjans del segle XXI la temperatura podria pujar entre $2^{\prime} 5$ i $3^{\prime} 5^{\circ} \mathrm{C}$ a l'àrea mediterrània. El principal impacte d'aquest canvi climàtic ja es manifesta en la major freqüència i durada de les sequeres, l'augment dels fenòmens extrems, la variació dels règims fluvials, la disminució de les pluges $\mathrm{i}$ el canvi de llur distribució temporal... (Asunción HIgueras, 2004; RoIs, 2010). Així, doncs, en un estudi històric cal observar els accelerats canvis ambientals que ha provocat i provoca la societat industrial. 
La conca del Vinalopó té una xarxa fluvial molt poc jerarquitzada, amb moltes àrees endorreiques o de difícil drenatge $i$, actualment, amb connexions antròpiques de la xarxa o àrees dessecades. Segons Rosselló Verger (1977: 59) el riu Vinalopó abarca una conca de $2.340 \mathrm{~km}^{2}$ que podrien ser drenats pel riu, però les àrees endorreiques redueixen la superfície exorreica que drena el riu a $1.705 \mathrm{~km}^{2}$. Al curs alt del Vinalopó apareix el curt riu Marjal que, com assenyala l'etimologia àrab del seu nom (marîy significa prat humit), és el primer exemple del sector amb difícil drenatge. En un plet de 1815 es fa referència al caràcter pantanós de les terres d'aquest sector:

quasi todas son marjales y llenas de humedades, por manera que en los años lluviosos están brotando agua por muchas partes y lejos de aprovecharles el riego, se inutiliza por tanta humedad la producción. ${ }^{3}$

Un antic sector palustre dessecat es localitza al Salze (Beneixama). Prop de la Canyada de Biar també hi havia una àrea d'aigües estancades i altra a la partida de la Foia.

Al terme de Villena existien diverses conques endorreiques o semitancades. La més gran era la Llacuna, prop del nucli urbà, amb una làmina aquàtica d'unes 740 hectàrees. A més a més, l'aiguamoll s'estenia per un àrea humida formada per les partides de San Juan, la Macolla, la Rajal, los Prados del Lancero i el carritxar, localitzades al sud de la Llacuna, I'horta i la ciutat de Villena, amb un drenatge imprecís a través d'un portell en Santa Eulàlia. Altre sector semitancat és el Hondo de Carboneras, una cubeta de 250 hectàrees. I altre és la petita àrea de difícil drenatge de las Moratillas.

La llacuna de les Salines, a la part occidental de les Valls del Vinalopó, és una depressió endorreica que acumula cabals subterranis i superficials d'un àrea d'uns $100 \mathrm{~km}^{2}$, en una superfície líquida de 125 hectàrees. Al sud apareixien dues zones reduides de difícil drenatge: el sector endorreic de les Cases del Senyor (Monòver) i el del Fondó de les Neus.

El riu Vinalopó forma un con al.luvial al sud d'Elx on podem distingir a gran trets dos espais humits: I'Albufera d'Elx al litoral i els Carritxars, Almarjals i la Bassa Llarguera a l'interior. Un extens corredor comunica ambdós aiguamolls, són els Saladars de destacat ús comunitari, com la resta d'estanys esmentats.

Aquesta és la geografia, l'espai físic d'aiguamolls i terres de tendència a l'aridesa on comunitats, persones i natura es relacionen. La humanització del medi ens fa distingir entre sequedat i sequera. Aquesta última té un pro- 
cés, una percepció i una construcció social històrica. Una sequera és una escassesa duradora d'aigua. Carència explicada no únicament per la pluviositat i la temperatura, elements generals de tota categoria climàtica, sinó també cal introduir com a variables la deforestació, l'erosió, les dessecacions, les activitats agropecuàries, extractives i, en definitiva, productives. És a dir, l'acció humana pot alterar el medi ambient de tendència a la sequedat i fer-lo més propens i vulnerable a les sequeres (Pérez Cueva, 2001. del Moral, 2004). Hem de pensar que el model conceptual i econòmic demana cada dia més i més aigua, la qual cosa fa que la característica bàsica del clima mediterrani, la sequedat, es convertisca en sequera. És a dir, la nostra percepció actual de la natura es perversa, doncs considerem que el nostre problema, la sequera, està motivat per un ecosistema imperfecte que hem de dominar amb la tècnica i l'obra hidràulica, unes tècniques i gestió de l'aigua totalment diferents a les tradicionals, camperoles i locals.

Un paisatge natural està integrat per una sèrie d'elements dinàmics -relleu, sòl, aigua, aire, llum, microorganismes, vegetació, fauna- que configuren un ecosistema viu. L'aigua és un element clau dels ecosistemes, forma part d'un conjunt congruent amb els seus components. Allò que confereix un caràcter particular al paisatge natural és la relació que mantenen l'aigua, la terra i el clima. Així, doncs, les varietats vegetals i faunístiques existents formen part d'aquesta relació orgànica. Aquesta interdependència inicia la seua dissociació quan l'aigua, element natural, passa a ser considerat recurs per a usos productius humans i són eliminades o posades en segon pla la resta de dimensions naturals, socials i culturals, encara que són imprescindibles per a la vida i indirectament per a l'activitat productiva (Tello, 2005: 275. Galindo, 2006: 64).

Aquest és el cas del nous agroecosistemes, tant de secà com de regadiu. Principalment a les hortes, l'aigua és extreta del seu cicle natural per a integrar-la en un nou circuit, exigent d'unes altes quantitat i qualitat d'humitat i de calor. Així, doncs, la sequera, no en termes de precipitacions, sinó de producció de collites, pot aparèixer. Més vulnerables són els agroecosistemes a una major demanda social d'aigua. És a dir, la nova interdependència entre terra i aigua capturada tendirà al desequilibri quan un dels components es descompense, bé per l'increment de l'àrea conreada, pel descens dels nivells hídrics, per l'augment de les necessitats de subsistència del collectiv o per l'acumulació d'excedents que pot portar a unes transformacions del sistema productiu i ecològic.

Passem a analitzar com gestionaven l'aigua les comunitats rurals del Vinalopó a les centúries modernes i com s'obrí un clivell d'insustentabilitat al sistema ecointegrador vigent als segles XVI, XVII i XVIII. 


\section{LA GESTIÓ ECOINTEGRAdORA de L'AigUA PER LA COMUNITAT RURAL}

En aquest capítol ens interessa observar com el camperolat preindustrial concebia la relació entre sòl i aigua, com gestionava el territori a petita escala a les valls i muntanyes del Vinalopó. La comunitat local agrària posseeix un sistema cognitiu de la natura i dels seus components que, integrats a l'agroecosistema, tendeix a la conservació i reproducció dels recursos naturals mantenint la diversitat biòtica. El camperolat usa els elements i processos naturals, però aquest paisatge natural transformat i humanitzat és un conjunt compost d'elements agraris i ambientals que mantenen i afavoreixen dues característiques bàsiques ecològiques: l'heterogeneïtat espacial i la biodiversitat. Les cultures tradicionals preindustrials -això és, precapitalistes i no mercantilitzades- tendeixen a implementar i desenvolupar sistemes ecològicament correctes i estables per a l'apropiació dels recursos naturals. El camperolat té una estratègia multiús per a la gestió dels ecosistemes i dels nous paisatges humanitzats (Toledo, 2008: 55). Una estratègia coevolutiva que agrupa factors ecològics i socioeconòmics (Cariño, 2013).

La tecnologia hidràulica transmesa ens informa del sistema cognitiu dels agricultors. El camperolat posseïa un evident coneixement sobre el cicle de l'aigua. Els llauradors coneixien les tècniques aplicades, senzilles, que no exigien coneixements teòrics complexos, sinó una acumulació i transmissió d'experiències enquadrades al seu marc sociocultural (Sevilla Guzmán, 2006: 204). Posseïen un alt grau de comprensió dels fluxos superficials i subterranis de l'aigua, que utilitzaven des d'una actuació sistèmica, això és, amb uns pressupostos d'eficiència social i ecològica i unes relacions d'ús i apropiació dels recursos hídrics que permetia llur recuperació i reposició.

Moltes obres hidràuliques locals són polivalents. Per exemple, una terrassa permet la infiltració de l'aigua, aporta el component hídric al cultiu, evita l'erosió i augmenta la deposició de matèria orgànica. L'ús de l'aigua obligava als agricultors a fer una reflexió sobre el cicle de l'aigua, perquè la qüestió hídrica va més enllà del reg de les parcel.les, ja que plou sobre els conreus, s'infiltra l'aigua als camps i a continuació hi ha brolladors. El camperolat es plantejava l'estratègia global del maneig de l'aigua, no únicament limitada a la captura hídrica als aqüífers o al reg de les parcel.les. Al llaurador li preocupava la humitat dels camps, la distribució homogènia de l'aigua de pluja, el control de les avingudes... No es limitava la seua atenció per l'aigua exclusivament al creixement de la planta, sinó també a la seva capacitat erosiva i destructiva, al transport de matèria orgànica o a la recàrrega dels aqüífers i les capes freàtiques.

4 Arxiu de Protocols Notarial de Monòver, Notari Miguel Pérez, any 1760, actes de conveni i concòrdia del 29 de Febrer, 21 de maig i 14 de novembre de 1760. 
Per a l'anàlisi de la gestió hidrològica local anem a observar diferents tècniques aplicades a les zones perifèriques, fora dels grans espais de regadiu permanent ja presentats en altres estudis (Hermosilla Pla, 2007). De l'extens terme de Monòver tenim una nombrosa documentació sobre l'abastiment a partir d'aigües d'escorrentia. Tres exemples de l'any 1760 ens permeten observar altres tantes variacions de cabals i llur captació ${ }^{4}$. Un és l'aprofitament de les aigües de pluja concentrades en una rambleta instal.lant una rafa eo assut al llit del col.lector per extraure l'aigua cap a les parcel.les que es volen regar. Altre tipus de maneig és l'aprofitament del descens superficial de l'aigua de pluja intensa pels vessants de les muntanyes, derivant-les mitjançant rases i parapets de pedra, terra i matolls (coladores) cap als bancals o cap a una bassa. Una tercera varietat és l'ús de surgències d'aigua es espais de drenatge insuficient a causa de precipitacions torrencials o de filtració subsuperficial i d'aqüífers. La captació d'aquestes aigües de marjaletes precisava l'excavació de rases, canals i séquies sempre descobertes, transportant-les directament a les parcel.les o emmagatzemant-les en un safareig.

El primer exemple esmentat de Monòver són les boqueres que s'adapten a les característiques locals, doncs, únicament porten aigua torrencial quan les rambles s'omplin per les aportacions de rierols i vessants. Les boqueres són obertures de gran secció (en poden assolir més $\mathrm{d}^{\prime} 1 \mathrm{~m}^{2}$ ) que capten l'aigua dels collectors lateralment per portar-la als camps i bancals per un ample canal. Les boqueres posseeixen gran capacitat volumètrica per absorbir les crescudes de rambles, barrancs i rierols, a diferència de les sèquies de distribució ordinàries que són de reduït cabal. Amb aquesta tècnica de captació i transport de l'aigua eventual de barrancs i rambles, els camperols regaven de tant en tant diverses parcel.les de secà. La construcció es feia de materials de l'entorn: pedra irregular, cantals i terra. Els camperols construien i mantenien aquestes estructures hidràuliques, doncs la força de les crescudes desbarataven les boqueres.

Les boqueres constaven de diversos aparats hidràulics construïts. Al llit de la rambla es construïa una rafa, un assut $o$ un dic que en uns casos consistia en un blocs ciclopis disposats com a parapets $i$ en altres casos n'era una estructura regular de maçoneria i argamassa. L'assut derivava el cabal tempestuós cap a la boca de gran secció del canal, que podia estar excavat a la terra o a la roca i, en ocasions, reforçat per murs de pedra. Amb la pràctica d'aquesta tècnica al camperol no li preocupa la impermeabilització de les obres hidràuliques, ja que es tracta de capturar elevats cabals esporàdics que circulen a gran velocitat per una topografia de grans pendents. La longitud del canal varia d'unes desenes de metres a uns quilòmetres. Per a superar desnivells de rambles encaixades o altres elements geogràfics, ocasionalment es construïen mines de transport. 
Els llauradors contribuïen amb el seu coneixement del medi al maneig de l'aigua mitjançant l'observació, la planificació, la creació i gestió d'elements hidràulics. Les tradicionals boqueres operaven al ritme dels cicles climàtics, colllaborant amb la natura per a un aprofitament eficient de l'aigua i dels nutrients. L'escorrentia concentrada permetia unes periòdiques inundacions blanes de les parcel.les de secà, acompanyades de processos de sedimentació de materials i microorganismes rics en nutrients i fertilitzants. A l'agricultura tradicional els cultius i les feines agrícoles s'adaptaven al règim d'humitat del sòl, que era completada per les aportacions equinoccials de les boqueres. Els canals aportaven aigua i nutrients durant les tempestes de la tardor o la primavera a les parcel.les sembrades de cereals o plantades de vinyes, oliveres o ametlers. Els canals tenien sobreeixidors que permetien dirigir l'aigua de les avingudes cap a la rambla quan el cabals torrencials no eren adequats a la humitat del sòl ni als conreus (Gascó i Gascó, 1999).

Aquesta tècnica, usada fins fa unes dècades a les comarques del Vinalopó, està documentada principalment al lligalls judicials pels abundosos plets entre camperols que lluitaven per a aquestes aigües esporàdiques. Moltes boqueres eren propietat d'un particular, havien fos constrüdes per un agricultor. Però hi havia boqueres compartides per dos o més camperols i, de tant en tant, sorgien dissensions per l'ús de les aigües eventuals. Per exemple, el mostassà de Petrer intervingué en un conflicte entre dos llauradors per una boquera en la partida del Guirney, dictant l'oficial local el 12 de maig de 1681 que la mitat de la aygua a de entrar en la terra y oliveres de dit Batiste Peres y la altra mitat en la terra y oliveres de Thomas Brotons ${ }^{5}$. A la universitat rural de Montfort la boquera que da riego a las tierras de secano que hi ha vora el riu Vinalopó forma part de les estructures hidràuliques que el sequier local $i$ les institucions municipal vigilen, la qual cosa realça el valor d'aquestes aigües esporàdiques als municipis amb disponibilitats hídriques reduïdes i demandes socials creixents.

Altres tècniques per a obtenir regs esporàdics de les parcel.les són les obres realitzades per aprofitar les aigües pluvials que circulen pels vessants. La infraestructura creada per a captar les aigües tempestuoses va des de la creació de terrasses als vessants de les muntanyes per a laminar el corrent i, alhora, provocar la infiltració a les parcel.les, a la construcció d'obres hidràuliques de reduïda envergadura. Les rafes, els assuts, els dics o les

5 Arxiu Municipal de Petrer, Caixa 37, exp. Aquests plets no es debaten únicament al marc de la justícia local, sinó també arriben a les instàncies judicials del regne, com és la disputa pel dret d'ús de mitja boquera en Petrer (ARV, Escrivanies de Cambra, any 1790, exp. 172, full 87) $\circ$ el plet que afecta a diversos propietaris d'Elx (ARV, Escrivanies de Cambra, any 1780, exp. 83, full 95). 
boqueres capten l'aigua concentrada als col.lectors fluvials; els marges, les parades o els murs són construïts als vessants per a aprofitar l'aigua de vessament difús. Aquestes parades estan fetes de pedres irregulars, terra, branques i herbes. La seua funció és tallar transversalment el vessant de la muntanya per a frenar la làmina d'aigua, dirigir-la i concentrar-la a les rases, conductes, regadores, buques i alveos. Aquests elements poden tenir una reduïda longitud o poden ser llargs parapets d'uns centenars de metres. La inversió realitzada en capital és nul.la, d'acord amb la capacitat dels camperols que conreen aquestes terres de secà. Per a la seua construcció $\mathrm{i}$ manteniment l'agricultor fa una inversió de treball familiar. Cavanilles (17951792: II, 255) féu una detallada descripció d'aquest sistema al proper municipi d'Agost, on els camperols han romput pujols i tossals,

Las quales dispuestas en graderías se trabajan con comodidad, y reciben fácilmente algún riego en tiempos de lluvias; á cuyo fin se han abierto canales que se comunican, y tomada el agua en los sitios altos de las arroyadas y barrancos se conduce largo trecho á las heredades. Alguna vez en Julio rebosan de agua los canales sin descubrirse nube, por haber llovido en los montes, cuyas vertientes caen á la espaciosa hoya donde está Agost [...] Extrañará ver salir los labradores hacia sus haciendas quando empieza a tronar, ó amenaza alguna tempestad: los truenos, que en otras partes sirven de señal para retirarse á sus habitaciones, lo son aquí para desampararlas y salir en busca de las aguas y deseado riego: se fecundan entonces los olivos, higueras, almendras, viñas y algarrobos; y el suelo entero se mejora con el cieno que traen las aguas. Para que éstas no maltraten los ribazos, ni los excaven al caer, suelen algunos como el citado Visedo formar conductos ó cañerías por donde pasa el agua oculta de los campos altos á los inferiores. Los canales ó pequeñas acequias están siempre abiertos y bien limpios esperando lluvias, que por desgracia son muy raras en aquella comarca.

Aquesta tècnica d'aprofitament d'aigües tempestuoses és abundosa a les muntanyes de Montfort. Al llarg del segle XVIII davant l'alcalde ordinari de Montfort, com a jutge local, són interposades causes relacionades amb l'aigua de reg. Un buidatge minuciós d'aquesta sèrie arxivística ha permet conèixer la importància atorgada per la comunitat rural a les aigües pluvials $i$ vessants ${ }^{6}$. Derivar aigua de les precipitacions torrencials permetia el reg eventual, però de gran valor, de parcel.les plantades de vinya, olivera, cereals i inclús de figueres vora les canyades o vessants muntanyenques. Un fragment d'una sentència del jutge local emesa el 23 de juny de 1735 afirma... que en

6 Arxiu Municipal de Montfort, Juzgado, llig. 1.106-1.153.

7 AMMf, Juzgado, llig. 1.107, exp. 5, full 52 
esta Universidad de Monforte es estilo y practica de tiempo inmemorial el que las tierras de campo que confinan con montañas reales deven gosar y gosan de los realencos confinantes en ellas por donde condusen las aguas pluviales que las riegan?.

Aquest dret apareix a les actes de compra. La importància d'una captació temporal d'aigües vessants pluvials és evidenciada quan a les actes notarials s'especifiquen les vessants de tossals i pujols públics dels quals obtenen els camperols fluxos superficials de pluges torrencials. Per exemple, la transmissió d'unes parcel.les de vinya i terra blanca per a cereals puntualitza que foren assenyalats sus ensanches y aguas vesantes para riego. $O$ indica explícitament els paratges, turons i vessants amb drets per a recollir aigua pluvial: las laderas correspondientes que bajan por el frente de las Lomas y tierras llamadas de la Buytrera ${ }^{8}$.

Els 27 plets oberts davant l'alcalde ordinari de Montfort entre 1730 i 1787 per aquestes aigües eventuals són iniciats per l'enfrontament entre camperols per l'ús dels cabals esporàdics. La lluita per l'aigua vessant porta als llauradors a assolar els parapets construïts pels colindants per a dirigir l'aigua a les seues parcel.les. Els perjudicats argumenten l'ús immemorial de l'aigua pluvial o que els seus camps reben l'aigua vessant perquè estan en el curso pluvial de las aguas naturales [...] de manera que la que llegue a caer en ella, con prezición, ha de derramar en las tierras de dicho Abat'.

\section{Clivells d'insustentabiltiat: el transvasament Xúquer-Vinalopó}

Hi ha una imbricació entre la gestió de l'aigua, els usos del sòl i l'organització del territori. Això és un aspecte destacat a la bibliografia existent. Així, del Moral (2004) destaca "la necesidad de situar la gestión del agua en un marco de política territorial". La planificació, concepció i construcció d'un sistema hidràulic no pot desenvolupar-se sinó com un instrument imbricat amb una determinada política territorial. Cal una gestió integrada al territori de l'aigua, amb el seu valor natural, cultural, patrimonial i simbòlic. L'absència d'aquesta visió pot provocar desequilibris territorials. En conseqüència, parlar de política hidràulica significa parlar de les formes d'ocupació i organització del territori. La planificació hidrològica ha de ser entesa com un element d'una determinada política territorial, per la qual cosa la gestió de l'aigua forma part d'un marc de referència territorial.

La conca hidrogràfica pot ser el marc de referència territorial on la gestió

8 AMMf, Juzgado, llig. 1.138, exp. 3 i llig. 1.148, exp. 1, full 4t.

9 AMMf, Juzgado, llig. 1.138, exp. 2. 
conjunta d'aigua i espai siguen inseparables. Indubtablement, el riu Vinalopó no compta amb una conca fluvial d'envergadura, equiparable a d'altres valencianes, però per a les comunitats camperoles dels senyorius era un marc de referència indefugible pel caràcter local i comarcal de l'economia agrària preindustrial. Encara que a l'actual bibliografia consideren la bioregió com a marc imprescindible de la gestió integral d'aigua i territori, entenent la bioregió com les conques formades naturalment on els paràmetres que regulen aquesta regió governen la relació entre flora, fauna, aigua i territori (Barlow / Clarke, 2004: 340-341), l'actuació política desfigura aquesta concepció sistèmica de la conca fluvial. A la geopolítica internacional del nou liberalisme, els rius transnacionals pateixen aquesta divisió de la conca natural pels conflictes fronterers i polítics, per bé que als fòrums es reivindique la unitat de la xarxa fluvial d'un curs d'aigua superficial i/o subterrània (Ayeb, 2001: 57).

El riu Vinalopó, terra de frontera internacional a l'Edat Mitjana, era un riu transnacional que patí la divisió de la conca natural pels conflictes fronterers i polítics. La petita bioregió es dividí en dues unitats polítiques. L'organització política i els poders jurisdiccionals de l'etapa medieval van influir en la posterior política hidràulica. A la conca del Vinalopó es poden distingir, amb molta claredat, dos sectors al moment de la competència per l'aigua. Un primer sector abraça la capçalera del riu Vinalopó, les quatre viles reials valencianes de Bocairent, Banyeres de Mariola, Biar i la Vall de Beneixama. Aquesta comarca gaudeix del privilegi reial d'ús exclusiu de les aigües del Vinalopó, afluents i brolladors. L'altre sector comprèn l'espai de la conca entre Villena, al regne castellà de Múrcia, i Elx, a la nova governació valenciana d'Oriola, és a dir, la major extensió de les comarques del Vinalopó. Dins d'aquest sector els conflictes intercomunitaris se succeeixen indistintament entre totes les viles, però sempre hi ha un lloc sobirà i un altre de jussà. Ambdós sectors són totalment independents en l'organització, distribució i gestió de l'aigua.

A la conca mitjana i baixa del Vinalopó la conflictivitat intercomunitària per l'aigua té una protagonista principal, la vila d'Elx. Tot el curs del riu-rambla, des de l'àrea palustre de Villena fins el con al.luvial il.licità, va estar mediatitzat, en part, pels interessos dels propietaris del regadiu d'Elx. Durant la Baixa Edat Mitjana, Elx va controlar l'aigua de gran part d'aquesta conca per al desenvolupament d'un sistema hidràulic periurbà a la plana al.luvial de la desembocadura.

Però Elx únicament va mantenir el control hídric de la conca del Vinalopó fins a la darreria del segle XIV. Des de l'any 1392 la competència per l'aigua genera una pèrdua progressiva del predomini il.licità a favor dels senyorius de les Valls del Vinalopó, principalment Elda i Novelda. El control 
hídric, garantit per privilegis reials i per l'organització feudal de la conca mitjana i baixa pel llinatge manuelí, va entrar en crisi al segle $\mathrm{XV}$, centúria caracteritzada per la senyorialització de la conca, fragmentada entre diverses cases nobiliàries. La disminució del pes polític d'Elx en l'ordenació dels sistemes hidràulics suposa un augment de la conflictivitat amb les comunitats senyorials de la comarca de les Valls del Vinalopó.

Al voltant d'Elx, ciutat força activa a l'època moderna, s'amplià el regadiu. Cal remarcar els cultius predominants a l'horta i el procés de rompudes de noves terres. Si ens apropem als bancals observem que els conreus principals són el blat, la civada, l'ordi, la vinya, les palmeres, les hortalisses de la terra hortal i l'olivera, que necessiten més i més aigua. Una de les bases econòmiques del mon urbà d'Elx, la producció de sabó, va tenir com a sector fonamental la intensificació i ampliació de l'olivar al regadiu. El subministrament d'aigua per a l'horta il.licitana augmentà mitjançant nombroses obres hidràuliques i conflictes amb les viles jussanes del riu Vinalopó pels limitats recursos hídrics.

En un context de lluita pels cabals de la conca del Vinalopó, es plantejaren els primers projectes de transvasament d'altres conques al Vinalopó. Elx planteja derivar aigua del riu Xúquer al Vinalopó l'any 1420. La data és simptomàtica, ja que la vila ha perdut l'hegemonia sobre les aigües de la Llacuna de Villena, de la copiosa Font del Xop i de les aigües corrents pel riu Vinalopó. Per a portar aigua del riu Xúquer, els consellers il.licitans entren en contacte amb els consells de Saix, Villena i Chinchilla. Villena respongué, després de donar permís per a que passen els tècnics anivelladors pel seu terme, que

"de presente nos no podemos contribuir ni dar cosa alguna por muchas dubdas que tenemos que la dicha agua non podra venir aca pero si la dicha agua sallir podia e seyendo puesta en tales terminos que la espirencia de los omes conosciesen que podrían venir a effecto a la sajon faremos e pagaremos sueldo por libra lo razonable fuere de faser" (Glick, 1988: 166).

Els regidors de Villena plantegen dos factors que influeixen "en lo que toca al sacar agua del rio Chuquer", és a dir, en la dificultat del transva-

10 Actualment els transvasaments i les transferències d'aigua es basen en un elevat consum energètic fòssil, elèctric, per això el principi físic de la circulació per gravetat ja no és requisit indispensable per a eixes obres hidràuliques. L'obstacle rau als efectes econòmics i ambientals de l'alt consum energètic, però els oligopolis energètics pressionen per a la realització de les grans obres de transvasament pels beneficis crematístics que albiren. Un exemple del consum energètic en ARROJo AGUDO (2003: 68-69) i altre exemple sobre el lobby elèctric en PRADA, 2003. 
sament d'aigua del Xúquer al Vinalopó. Un primer factor és el geogràfic, això és, els obstacles per a construir un canal de 100 quilòmetres per una topografia accidentada, amb desnivells orogràfics insalvables per a un aigua que circula per gravetat, sinó es fan llargs túnels, aqüeductes i sifons ${ }^{10}$. Cal afegir la falta d'informació sobre el relleu, els sols i el cabals. Per a conèixer les característiques del terreny i del recorregut del riu Xúquer i del futur canal, des dels primers projectes de transvasament es realitzaren rutes de reconeixement dels trajectes fluvials. A les breus memòries elaborades es reconeix els impediments orogràfics del transvasament.

Un segon factor que determinà el continu ajornament del transvasament fou la despesa econòmica de l'obra hidràulica, excessiva per a les hisendes locals que havien d'assumir-les. Els regants beneficiaris i les tresoreries municipals, a més d'aportacions senyorials, feien càlculs de cost-benefici ja que mancaven ajudes, subvencions, crèdits rebaixats o pressupostos estatals que assumiren les elevades despeses d'aquestes grans obres hidràuliques. Censals, préstecs a canvi, repartiments i arbitris eren els recursos financers comuns dels governs locals per a pagar les despeses hidràuliques. L'any 1628 la ciutat d'Alacant participà al projecte de transvasament Xúquer-Vinalopó, fent un càlcul de 700.000 lliures per a tot el projecte, comprometent-se la ciutat alacantina en 150.000 lliures i la resta haurien d'aportar-les les altres viles beneficiàries (Glick, 1988: 161). Al comparar aquestes dades amb les despeses d'altres grans obres, observem l'excessiu preu del transvasament: el pantà de Tibi, finalitzat a la darreria del segle XVI, costà 58.000 lliures (Alberola Romà, 1984: 45) i el pantà d'Elx finalitzat el 1646 costà 21.000 lliures $^{11}$.

Després dels fracassos del primer intent de transvasament de 1420, al llarg del segle XVI apareixen nous projectes. El 1528, en una conjuntura de recerca de noves dotacions per a l'horta d'Elx, el consell particular inicià tràmits per a l'anivellament i transvasament d'aigües dels rius Xúquer i Segura. El 1568 intervingué el marqués d'Elx i es prodüren els primers anivellaments i diferents obres als terrenys per on haurien d'anar els canals amb aigua del riu Xúquer. El 1628 s'interessà la ciutat d'Alacant, però l'oposició de la ciutat de València, que posà una demanda en la Reial Audiència, frenà els nous intents de derivar aigua de la conca del Xúquer al Vinalopó (Piqueras Haba, 1985: 129-130. Glick, 1988: 161. Brú Ronda, 1992: 87). L'any 1668, en un període de sequera i greu esterilitat segons declaren els consellers il.licitans, es torna a projectar el transvasament. El pedrapiquer $i$

11 Bernabé GIL (1996) aporta exemples d'obres hidràuliques dels segles XVI i XVII amb pressupostos i despeses, no arribant cap d'elles a la quantitat pressupostada per al transvasament Xúquer-Vinalopó. 
matemàtic Francisco Verde estigué 23 dies realitzant estudis d'anivellament amb dos ajudants ${ }^{12}$. No es féu l'obra per les dificultats tècniques, la longitud i perquè "se ha considerat que lo gasto ha de ser exçesiu i que's pasarà de cent milia lliures y lo temps que se ha de gastar en portar dita aygua ha de ser molt ${ }^{\prime 13}$. Els factors financers i orogràfics tornaven a frenar el transvasament del Xúquer al Vinalopó. Un segle després, el 1776, es tornà a planificar però fou refusat per irrealitzable (Ramos Fernández, 1970: 262). Al segle XIX novament es reprén la idea del transvasament, però tampoc es realitzà (Díaz Marín, 2000). La tenalla crítica de la realitat financera i dels límits tècnics provocà els fracàs del transvasament. L'aigua del Xúquer no anà enlloc.

Amb tots els projectes esmentats de transvasament d'aigua del riu Xúquer al riu Vinalopó, els promotors il.licitans traspassaren la conca del Vinalopó com a marc territorial de gestió. Trenquen la gestió integral d'aigua i territori al marc de la bioregió i renuncien als mecanismes de gestió de l'escassesa climàtica i hidrològica. L'escassesa física de l'aigua derivada dels condicionants geoclimàtics constitueix el principal limitant per al agroecosistemes ${ }^{14}$, però a l'agricultura camperola es crearen unes formes de vida i tècniques eficients coincidents amb aquest caràcter hidrològic. La gestió ecointegradora internalitzava les fluctuacions estacionals i interanuals, és a dir, l'escassesa hídrica, la sequedat i els períodes de sequera (Martínez Fernández, 2000: 22). Amb la planificació del transvasament Xúquer-Vinalopó els consellers d'Elx abandonen l'adopció de la gestió hídrica dels recursos renovables disponibles a la bioregió, renuncien a la gestió de la demanda d'aigua de l'agroecosistema adaptada al marc de la conca i incideixen més a la oferta d'aigua per a un regadiu en expansió. Mitjançant la tècnica es vol solucionar les creixents necessitats d'aigua, encara que fòra un límit insalvable fins l'ús de les energies fòssils.

Conceptualment, els promotors il.licitans del transvasament canvien els hàbits de pensament i de comportament davant la gestió de l'aigua. Amb els projectes d'una gran obra hidràulica de transferència interconques es planteja el cicle hidrològic com un sistema obert, intervingut i interromput, que pot solucionar l'escassesa d'aigua mitjançant la tecnologia. Es concep

12 Arxiu Municipal d'Elda, llig. 118, fulls 147-151. Francisco Verde treballà a la Sèquia Major d'Elx i a la nova sèquia de Boniol en la partida de les Alqueries (Arxiu Històric Municipal d'Elx, Secció $H$, llig. H/57, núm. 39).

13 AHME, Secció $H$, llig. $H / 105$, núm. 1.

14 No oblidem que la formació de sòl al paisatge muntanyenc de tendència a la aridesa també constitueix un limitant a alguns paratges del Vinalopó. 
l'administració de l'aigua i les obres hidràuliques des de la mecànica dels fluids. Des d'una visió ecointegradora, els projectes de transvasament revelen que la vila d'Elx i el seu agroecosistema ha superat la capacitat de càrrega del territori i dels seus ecosistemes, i els seus habitants augmenten la petjada ecològica i hídrica (Llamas, 2005. Tello, 2005: 306). A més, la quantitat d'aigua que demana la vila d'Elx fora de la conca del Vinalopó podia tenir uns impactes no mesurats als projectes: amb la detracció de cabals del Xúquer s'eliminen retorns al riu i als aqüífers de la conca emissora i a la conca receptora del Vinalopó s'han de gestionar el fluxos de fluids sòlids i de nutrients (Arrojo Agudo, 2003: 54 i 86).

\section{A tall de cloenda}

En un paisatge muntanyenc mediterrani de tendència àrida a l'estiu i de pluges torrencials equinoccials, la gestió de les escorrenties difusa i concentrada amb fluids sòlids i nutrients és una tasca del camperolat. Les comunitats rurals controlen i gestionen els processos de treball al voltant dels recursos comunals dels quals depenen ${ }^{15}$. El govern local del camperolat garantia un conjunt de pràctiques agràries conservadores dels recursos naturals i, al cas hídric, extreien aigua d'un ecosistema sense posar en risc el seu estat ecològic. Tenien pràctiques i mecanismes institucionals que incentivaven un consum racional dels recursos hídrics. Practicaven la racionalitat, és a dir, administraven l'escassesa amb eficiència i sustentabiltat (Tello, 2005: 281. Cariño, 2013: 25).

La projecció, construcció i actuació de canals, preses i dessecacions d'aiguamolls a les centúries modernes, denoten un clivell a la gestió hidrològica. El transvasament Xúquer-Vinalopó és l'exemple que hem presentat. Però la construcció dels embassaments d'Elx, Petrer i Elda i les dessecacions dels aiguamolls de Villena i Elx són altres casos de canvi ambiental a les comarques del Vinalopó. La construcció a l'any 1680 de la presa de Petrer d'una alçada de 13 metres, una grossària de 6 metres i una longitud màxima al coronament de 47 metres, és un exemple d'obra hidràulica que provocà alteracions ambientals importants $i$, com a conseqüència immediata, suposà el rebliment i la inutilització de l'embassament tres dècades després (Pérez Medina, 1997). El canvi tecnològic que significà la construcció de preses al sud valencià a finals del segle XVI i al llarg del XVII, portà artefactes més grans, de major envergadura constructiva que els coneguts fins ara. Front a l'intent d'abastar l'escassesa d'aigua amb noves obres -rígides i fixes- apa-

15 Els titulars feudals realitzen un control indirecte amb diferents formes de dominació, explotació i producció. 
regué una implicació imprevista: els canvis a l'entorn fluvial (Postel, 1997: 30-31). Imperceptiblement, la comunitat rural petrerina havia traspassat la línia de la preocupació pel context hidrològic i posà l'accent en una gran obra hidràulica. Cal destacar la participació política i financera del comte d'Elda en la construcció de l'embassament, com a interessat en augmentar les rendes senyorials mitjançant la millora de la producció agrària i la intensificació de l'explotació de la terra.

Al segle XVIII una de les línies d'actuació de la política hidràulica de les ciutats i dels interessats al regadiu del Vinalopó, es dirigí cap a l'aprofitament de les àrees humides. Els desguassos de les extenses llacunes $\mathrm{i}$ aiguamolls foren dirigits i finançats pels grans propietaris, per la noblesa feudal i per la corona. La Bassa Llarguera i els Almarjals, Carritxar i Saladar il.licitans foren dessecats en gran part durant el segle XVIII per obres de desguàs i canalitzacions promogudes pel duc d'Arcos, titular d'Elx. El projecte de dessecació de la Llacuna de Villena es plantejà l'any 1760 pel consell municipal d'Elx i fou assumit pels regidors de Villena. Però l'oligarquia urbana d'ambdues ciutats es trobà amb els interessos del marqués de la Romana, Pere Maça de Liçana, senyor de Novelda, i l'actuació definitiva de la Secretaria d'Hisenda de Carles IV.

La regressió de les maresmes litorals i dels aiguamolls interiors tingué un efecte social destacat: l'apropiació i privatització de comunals i propis que compensaven l'economia familiar d'un ampli sector rural. El canvi ambiental dels aiguamolls també tingué uns impactes al clima comarcal i a l'accentuació de l'escassesa hidrològica (Almenar i Diago, 2002: 377). El paper de la noblesa i de l'oligarquia local d'Elx i Villena cap a un creixement productiu econòmic i una acumulació primitiva de capital estan a l'origen de la sustentabilitat clivellada al Vinalopó modern.

\section{ReferènCIES BibliogràfiQues}

Alberola Romà, A. (2010): Quan la pluja no sap ploure. Sequeres i rivades al País Valencià en l'edat moderna, PUV, València.

Alberola Romà, A. (1984): El pantano de Tibi y el sistema de riegos de la huerta de Alicante, I. E. Gil-Albert, Alacant.

Almenar, R., Bono, E., Garcia, E., dirs. (2000): La sostenibilidad del desarrollo: el caso valenciano, PUV, València.

Almenar Asensio, R., Diago Giraldós, M. (2002): El proyecto necesario. Construir un desarrollo sostenible a escala regional y local, PUV, València.

Arrojo Agudo, P. (2003): El Plan Hidrológico Nacional. Una cita frustrada con la historia, RBA Libros, Barcelona. 
Arrojo, P. (2006): El reto ético de la nueva cultura del agua. Funciones, valores y derechos en juego, Paidós, Barcelona.

Arrojo, P., NARedo, J.M. (1997): La gestión del agua en Espanya y California, Bakeaz, Bilbao.

AsunCión HIGUeRAS, M. (2004): "Cambio climático: el impacto de nuestro modelo energético", Archipiélago. Cuadernos de crítica de la cultura, 61. ps. 27-34. AYEB, H. (2001): Agua y poder. Geopolítica de los recursos hidráulicos en Oriente Próximo, Barcelona.

Barlow, M., Clarke, T. (2004): Oro azul. Las multinacionales y el robo organizado de agua en el mundo, Barcelona.

Bernabé GIL, D. (1996): "Política hidràulica en la Espanya de los Austria", Alberola Romà, A., eds., Cuatro siglos de técnica hidràulica en tierras alicantinas, Universitat d'Alacant, Alacant, ps. 67-88.

BRÚ RondA, C. (1992): Los caminos del agua. El Vinalopó, València.

CarIÑo, M., ed. (2013): Evocando al edén. Conocimineto, valoración y problemàtica del Oasis de Los Comondú, Icaria Editorial, Barcelona.

CAVANILLES, A.J. (1795-97): Observaciones sobre la historia natural, geografía, agricultura, población y frutos del reyno de Valencia, 2 vol., Madrid (Ed. facsímil, València, 1987).

Cotarelo Álvarez, P. (2010): Los conflictos sociales del cambio climático, Libros en Acción, Madrid.

Díaz Marín, P. (2000): "Antecedentes históricos del trasvase del Júcar: la utopía hidràulica de la burguesía alicantina del siglo XIX", Congreso nacional sobe la gestión del agua en cuencas deficitarias, Alacant, ps. 49-55.

GALINDO, P., coord. (2006): Agroecología y consumo responsable. Teoría y práctica, Kehaceres, Madrid.

Gascó Montes, J.M., Gascó guerrero, A.M. (1999): "Adaptación de los cultivos y las labores al régimen de humedad de los suelos en la agricultura tradicional", Garrabou R., Naredo, J.M., eds., El agua en los sistemas agrarios. Una perspectiva histórica, Fundación Agentaria-Visor Dis., Madrid, ps. 85-94. Guck, T.F.. (1988): Regadio y sociedad en la Valencia medieval, Del Cenia al Segura, València.

Hermosilla PlA, J., dir. (2007): Los regadíos tradicionales del Vinalopó. Alto y Medio, Generalitat Valenciana, València.

LlamAs MAYORGA, R. (2005): Los colores del agua, el agua virtual y los conflictos hídricos, Real Academia de Ciencias Exactas, Físicas y Naturales, Madrid. Martínez Fernández, J., coord. (2000): Gestión alternativa del agua en la cuenca del Segura, Ecologistas en Acción, Múrcia. 
Martínez Fernández, J., Esteve Selma, M.A., coord. (2002): Agua, regadío y sostenibilidad en el Sudeste ibérico, Bakeaz, Bilbao.

Del Moral Ituarte, L. (2004): "Planificación hidrológica, mercado y territorio", ARrojo Agudo, P., coord., El agua en Espanya: propuestas de futuro, Ediciones del Oriente y del Mediterráneo, Madrid, ps. 205-216.

NAREDO, J.M. (1987): La economía en evolución. Historia y perspectivas de las categorías básicas del pensamiento económico, Siglo XXI, Madrid.

NAREDO, J.M. (2006): Raíces económicas del deterioro ecológico y social. Más allá de los dogmas, Siglo XXI, Madrid.

PÉREZ MEDINA, T. (2008): “El manejo campesino del agua en ambientes preindustriales del sur valenciano", XII Congreso de Historia Agraria, SEHA, Còrdova.

Pérez Cueva, A. (1994): Atlas climàtic de la Comunitat Valenciana (19611990), Conselleria de Territori, València.

Pérez Cueva, A. (2001): "Las sequías en tierras valencianas", Gil Olcina, A., Morales Gil, A., eds. Causas y consecuencias de las sequías en España, Universitat d'Alacant, Alacant, ps. 131-159.

Pérez Medina, T. (1997): "Agua para los regadíos meridionales valencianos. Las presas del siglo XVII de Elx, Petrer y Elda", Revista de Historia Moderna, 16, ps. 267-288.

Pérez MedinA, T. (2008): “El manejo campesino del agua en ambientes preindustriales del sur valenciano", XII Congreso de Historia Agraria, SEHA, Còrdova.

PIQUeRAS HABA, J. (1985): La agricultura valenciana de exportación y su formación histórica, MAPA, Madrid.

Postel, S. (1997): Reparto del agua. Seguridad alimentaria, salud de los ecosistemas y nueva política de la escasez, Bakeaz, Bilbao.

Ramos Fernández, R. (1970): "Proyectos para trasvase de aguas de riego a Elche", Cuadernos de Geografía, 7, ps. 259-272.

RoIs, C. (2010): "Cambio climático", DDAA, Claves del ecologismo social, Libros en Acción, Madrid, ps. 79-84.

Rosselló I Verger , V. (1977): “El riu Vinalopó. Viatge amb un poc d'història i més de geografia", Serra d'Or, núm. 219 (XIX), ps. 59-65. (lbídem, Revista del Vinalopó, 4 (2001), ps. 183-192).

SeVILLA GuZmÁN, E. (2006): De la sociología rural a la agroecología, Icaria Editorial, Barcelona.

Telo, E. (2005): La història cuenta. Del crecimiento económico al desarrollo humano sostenible, El Viejo Topo, Barcelona.

Toledo, V.M., BarRera-BAssols, N. (2008): La memoria inmaterial. La importancia ecológica de las sabidurias tradicionales, Icaria Editorial, Barcelona. 